\title{
Honey Bee Diversity in Urban and Peri-urban Agriculture and Urban Forest- Outlook Study from Bengaluru-Silicon Valley of India: A Review
}

Prem Jose Vazhacharickal ${ }^{1,3}$, K.S. Jagadish ${ }^{2}$, G. Eswarappa ${ }^{2}$

10.18805/ag.R-2327

\begin{abstract}
The "Silicon Valley" of India, Bengaluru is one of the fastest growing cities, with many middle-class residents growing fruits and vegetables in their private spaces. This kind of Localized food systems (LFS) has been considered not only for obtaining mental pleasure and health consciousness, but also food for home consumption. This outlook study examined the honey bee diversity and possibilities of integrating different honey bees in urban agriculture and forests across the Bengaluru city. The urban forestry study across the Bengaluru city revealed presence of 374 species with the highest species diversity in parks (291) followed by residential areas and layouts (164) showing species richness. Polyalthia sp. and Pongamia glabra were found to be the most dominated tree species around the Bangaluru city. Majority of the plant_species were offering good_foraging sources for honey bees, including Apis indica, Apis dorsata, Apis florea and Trigona iridipennis. The urban agriculture and urban forest system in the Bengaluru was ideal for bee-keeping, especially stingless bees, which could be easily reared with limited space and care. Thus, the urban agro-ecosystem and the possible pollination services through integrating honey bees could be very much useful in making the cities more sustainable and resilient.
\end{abstract}

Key words: Honey bee, Localized food system, Pollination services, Urban and peri-urban agriculture, Urbanization.

The pre-historic relationship between humans and honey bees exists based on long-standing interest (Cardinal and Danforth 2011; Kraft and Venkataraman 2015) of increasing crop production through pollination and maintain ecosystem stability, environmental quality and biodiversity (Abrol 2013). The Indian bee-keepers rear honey bees in a traditional system under semi-domesticated conditions amended with modern scientific practices (Kraft and Venkataraman 2015). Rearing of honey bees and harvesting of honey dates back to $7000 \mathrm{BC}$. and also known for the production of bee wax, bee venom, royal jelly and propolis besides production of honey. Honey bees plays an important role in natural pollination of cultivated as well as wild species of crop plants. Around $1 / 3^{\text {rd }}$ of the total cultivated crops of the world were pollinated by different species of bees, of which, honeybees were the most effective and reliable ones (Abrol 2013). Even though bee keeping is considered as an agricultural activity, they do not require land or compete with other farm animals and possible in areas with flowering plants for nectar and pollen. Different forest sites, agricultural farms, fruit orchards, poly-houses, green-houses and recreational parks could be utilized effectively for beekeeping. Stingless bees are the eusocial insects like other honey bees and quite appreciated for the value of the honey, pollen as well as various ecosystem services. Stingless bees differ from other honey bees due to the presence of a vestigial sting, lack of venom, mass provisioning for larvae and multiple queen system and lack of wax glands. Meliponiculture is the beekeeping method of stingless bees usually undertaken by traditional
${ }^{1}$ Department of Agricultural Economics, Rural Urban Center, University of Agricultural Sciences, Bangalore-560 065, Karnataka, India.

2Department of Apiculture, University of Agricultural Sciences, Bangalore-560 065, Karnataka, India.

${ }^{3}$ Department of Biotechnology, Mar Augusthinose College, Ramapuram-686 576, Kerala, India.

Corresponding Author: Prem Jose Vazhacharickal, Department of Agricultural Economics, Rural Urban Center, University of Agricultural Sciences, Bangalore-560 065, Karnataka, India.

Email: premjosev@gmail.com

How to cite this article: Vazhacharickal, P.J., Jagadish, K.S. and Eswarappa, G. (2022). Honey Bee Diversity in Urban and Periurban Agriculture and Urban Forest: Outlook Study from Bengaluru-Silicon Valley of India: A Review. Agricultural Reviews. DOI: 10.18805/ag.R-2327.

Submitted: 10-07-2021 Accepted: 19-11-2021 Online: 17-01-2022

communities or local people (Vazhacharickal and Jose 2016). Honey, pollen and resin are the important source of income in meliponiculture. The nests of stingless bees could be seen in building foundations, mud walls, stone walls and tree cervices. Tetragonula iridipennis is an important species of stingless bees, whose name appears due to triangular abdomen and iridescent wings. For building nest, they collect resins from trees which makes them called as Dammer bees (Vazhacharickal and Jose, 2018). Much importance are given to the large scale production of Apis indica and Apis 
Honey Bee Diversity in Urban and Peri-urban Agriculture and Urban Forest- Outlook Study from Bengaluru-Silicon Valley of.....

mellifera in Karnataka. Very little scientific studies were conducted in stingless bees in Bengaluru (Roopa et al. 2020). Stingless bees were much far ahead of medicinal properties of honey and plant pollination when compared to other honey bee.

\section{Urbanization}

Urbanization is a rapid process with historic transformation on a global scale with the replacement of rural culture with urban culture. Migration has a key role in this transitions, which is mainly governed by push factors and pull factors (Cohen 2006; Timalsina 2007; Satterthwaite et al. 2010; Vazhacharickal 2014). Urbanization brings spatial, economic, social, demographic and environmental changes with positive and as well as negative aspects (Weber and Puissant 2003; Nath 2007; Vazhacharickal 2014). According to UN (United Nations), it was predicted that $68 \%$ of the world population occupy in the urban areas by the year 2050 (UN 2019).

\section{Urban and peri-agriculture}

Urban and peri-urban agriculture (UPA) can be broadly defined as the production, processing and distribution of foodstuff from crop and animal production, fish and ornamental flowers within and around urban areas (Mougot 2000). The acronym UPA has been introduced by the Food and Agricultural Organization (FAO) and UPA mainly focuses on perishable and highly valuable products in limited spaces (Nugent 2000; De Zeeuw et al. 2011). The UPA fills the hunger gaps by enhancing the access and distribution of food in urban areas (Lee-Smith 2010). Currently, urban agriculture is being practiced for meeting subsistence needs, as a market-oriented activity, for recreation, or as a combination of all these components (Vazhacharickal et al., 2020).

\section{Bengaluru: The silicon valley of India}

Bengaluru, the capital of Karnataka State, is a rapidly growing megacity with a population $>10$ million. The study area $\left(2182 \mathrm{~km}^{2}\right)$ comprises of the Bengaluru Urban district, situated at an altitude between 875 and $940 \mathrm{~m}$ above sea level (a.s.I) (Fig 1). The climate is favourable with a mean annual rainfall of approx. $880 \mathrm{~mm}$ and a monsoon season lasting from June to October (Ramachandra and Kumar, 2008). Due to its large number of open green spaces and a

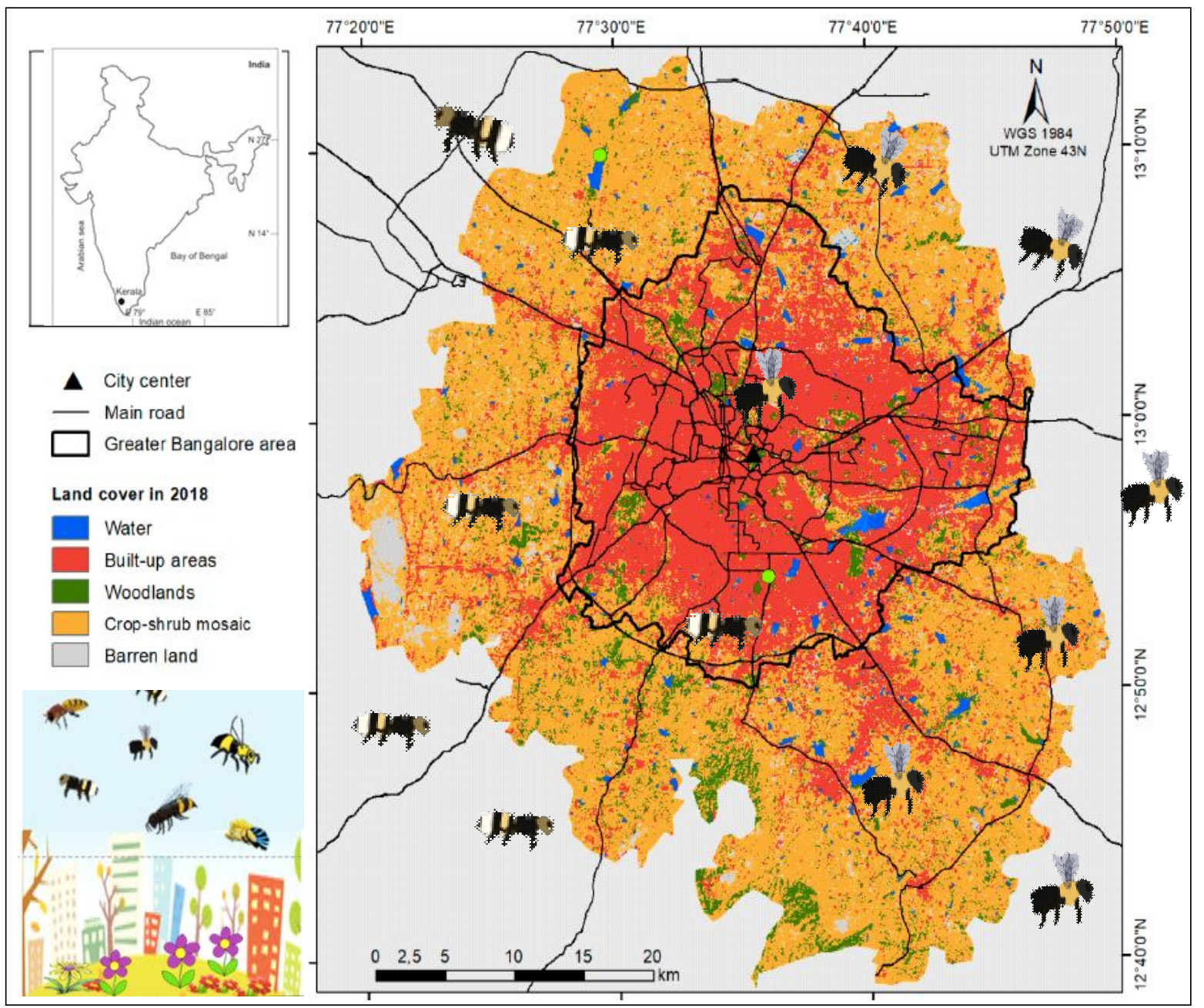

Fig 1: Overview of the Bengaluru urban districts showing the land cover classification. Modified after: Brinkmann et al. (2020). 
large series of partly interconnected wetlands and water bodies, the city was historically well known as the "Garden City" or "City of Lakes" (Sudhira et al., 2007).

\section{Urban and peri-urban agriculture: Bengaluru scenarios}

Little is known about the various UPA productions systems in Bengaluru. A study conducted by Gowda et al. (2012) on Magadi; one of the true peri-urban area with strong agricultural base show that the proportion of the net income from agriculture and livestock to the total income raised. The cooperative horticultural marketing by HOPCOMS in Bengaluru is an example of collective marketing by farmers in the peri-urban areas. Urban agriculture in Bengaluru flourish with the support of Garden City Farmers Trust; NGO which support urban farming, which is similar to Dr. Doshi's city garden methods suitable to reduced spaces such as balconies and terraces which depend on locally available materials like sugarcane wastes, polyethylene bags and household organic wastes and are targeted towards mainly domestic consumption ((Vazhacharickal and Buerkert 2011). The need for housing increases the value of agricultural land in urban and peri-urban areas and leads to their rapid transformation (Vazhacharickal 2014; Hoffmann et al., 2017; Vazhacharickal et al., 2020).

\section{Localized food systems}

In the context of increasing urbanization and globalization of agricultural production and marketing, localized food systems (LFS) have emerged as a theoretical framework to imagine and order methods to address the effects and impacts. Growing cities can have profound positive or negative impacts on their surrounding food producing areas and trend that is most often observed, negative impacts on food and nutrition security resulting especially from increasing pressure on the natural resources required to feed the urban population (Grinspan 2015). Another opportunity of UPA to contribute to the localization of the food system rises from its direct access to urban consumers and markets, which facilitates the expansion of direct marketing arrangements (Vazhacharickal et al. 2020).

\section{Middle class urban gardening}

Gardening is becoming fashionable among people of the new middle-classes and Urban gardening has long been a
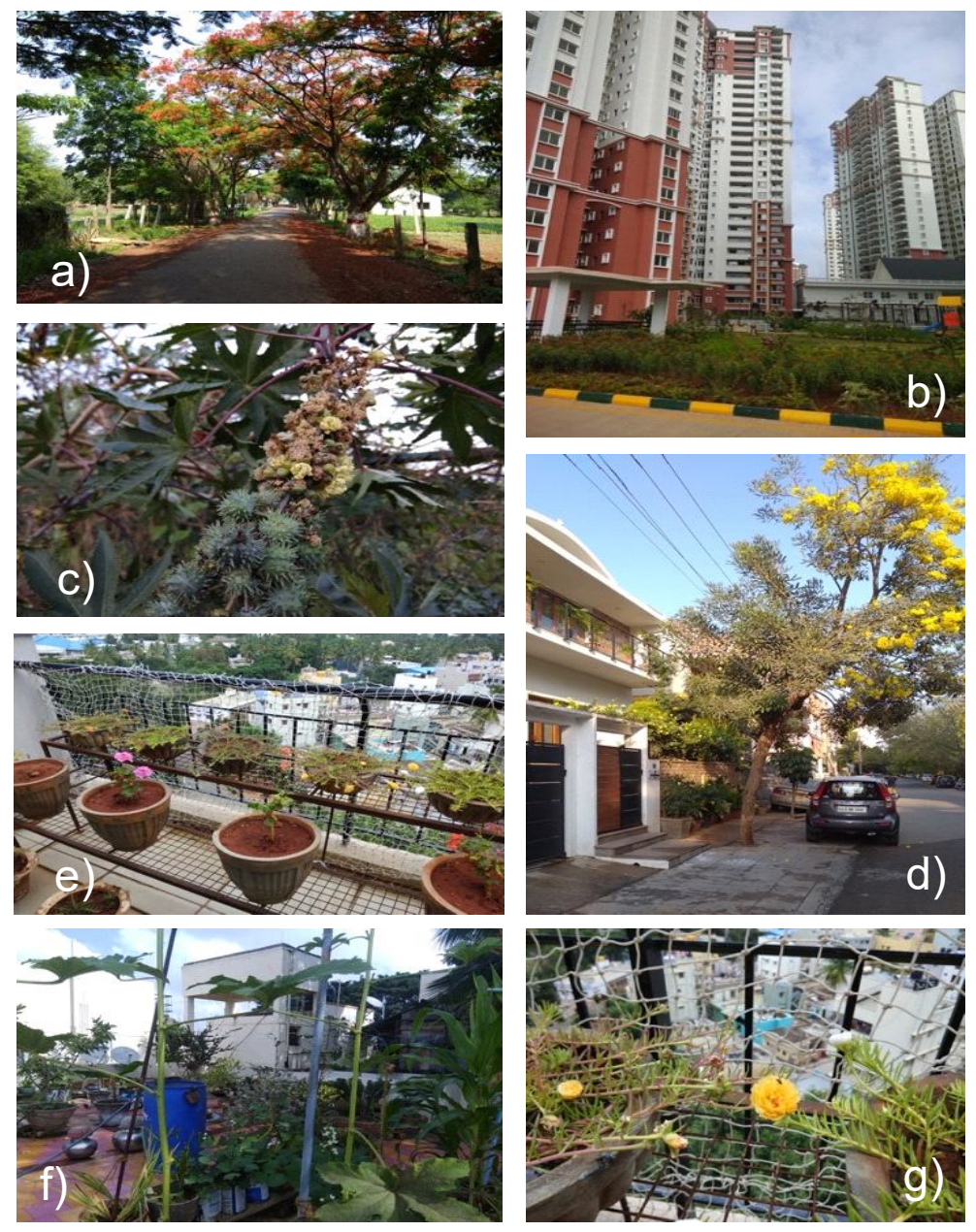

Fig 2: Description of the urban agriculture and urban forest across Bengaluru a) and d) avenue trees in GKVK and residential area; b: community park in flats; c) Ricinus communis in waste lands; e) and g) balcony gardens; f) terrace garden. 
working-class practice in places such as Bengaluru (Fig 2, 3; Frazier 2018). India's new middle-class is elusive and consists of a heterogenous group of people who are generally high educated and well-travelled and who carve out a social position between elite and working classes through consumption and leisure practices (Fernandes and Heller 2006; van Holstein 2019; Vazhacharickal et al. 2020).

\section{Organic terrace gardeners (OTGians)}

An increasing number of middle class residents in Bengaluru are growing fruits and vegetables for home consumption, motivated primarily by concerns about worsening health and food safety conditions and secondarily by declining green spaces in the city. organic terrace gardeners, most of whom self-describe as "OTGians", a title that originated with the Organic Terrace Gardening (OTG) Facebook group.
OTGians have created a vibrant community dedicated to sharing resources and knowledge about urban gardening, with the goal of reworking existing relations of food production and consumption in the city. Communication among members is mainly mediated through the group's FaceBook page and group identity is largely built on that platform (Grinspan 2015; Frazier 2018; Vazhacharickal et al. 2020).

\section{Garden City Farmers Trust (GCF)}

Garden City Farmers Trust (GCF) is officially registered as trust and started in activity way back in the year 1995 with the promotional work of its founder, Dr. B. N. Vishwanath. GCF's current major focus area is on promoting organic terrace and home gardening in the city of Bengaluru by conducting trainings and workshops, connecting
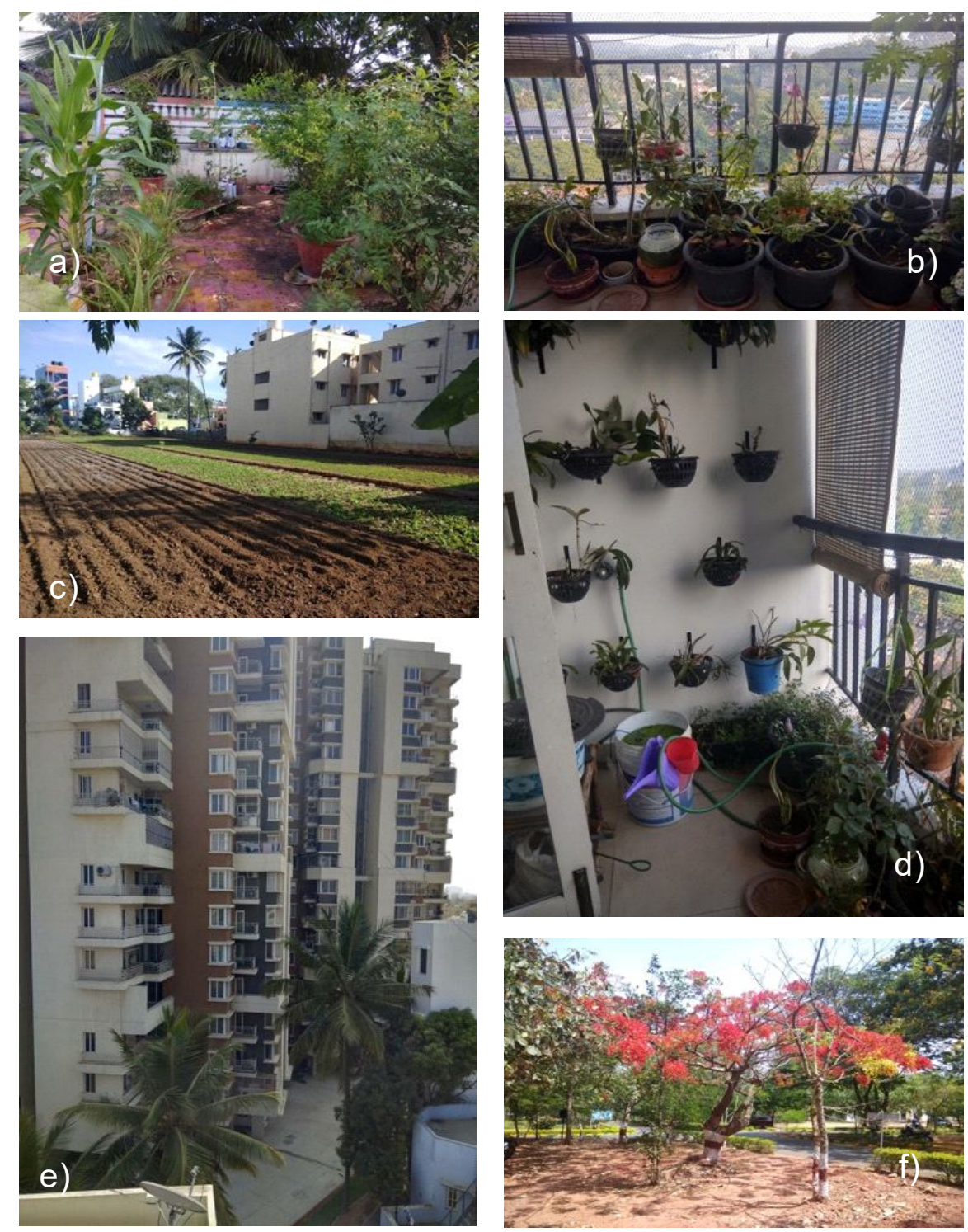

Fig 3: Description of a) terrace garden b) and d) balcony gardens c) urban agriculture practiced in vacant lands near to apartments e) flats showing balconies $f$ ) avenue trees with full blossom. 
practitioners and resources and promoting awareness of urban food growing through national and state-level seminars with a motto "Grow What You Eat and Eat What You Grow". The event "Oota From Your Thota" (or Food From Your Garden) is a quarterly event with a two-fold purpose: to bring urban practitioners and other interested people together to share their experiences and knowledge; and to connect urban gardeners and re-source provider (Grinspan 2015; Frazier 2018; Vazhacharickal et al. 2020).

\section{Balcony and terrace gardens in Bengaluru}

The Kannada term kaithota (literally "hand garden") refers to kitchen gardens that are common in rural house-holds, where women plant a few fruits and vegetables for consumption and flowers for religious worship near the edges of their home. The term kaithota and the broader term thota, meaning garden or plantation, are sometimes used to describe urban home gardens. Most of the urban gardeners have their garden on the terrace/balconies of their house or apartment of flats (Fig 2,3). Usually majority of the terrace gardens are container gardens which focus on ornamental plant and food plants especially vegetables, aromatic plants and fruit trees. The major input use and provisions include compost (kitchen waste and other brought outside), water (household supply), containers (plastic drums, vegetable wooden crats, used cement bags, old tyres and various styrofoam packing materials), cow dung and urine, neem oil cake and coco peat (Grinspan 2015; Frazier 2018; Vazhacharickal et al. 2020).

\section{Urban green spaces}

Urban green space provide an opportunity to increasing urban population to observe and interact with nature. Urban greenery and vegetations has a major role in providing ecosystem services, mental pleasure, satisfaction and social well-being of stressful urban life. Urban vegetation includes

Table 1: Trees recorded from single domestic gardens and shared apartment gardens in Bengaluru that are consumed as food and/or have medicinal use and/or religious significance and provision of foraging sources for honey bees. Modified after Jaganmohan et al. (2012).

\begin{tabular}{|c|c|c|c|c|c|}
\hline Scientific name & $\begin{array}{l}\text { Common } \\
\text { name }\end{array}$ & $\begin{array}{l}\text { Consumed } \\
\text { as food }\end{array}$ & $\begin{array}{l}\text { Medicinal } \\
\text { use }\end{array}$ & $\begin{array}{l}\text { Religious } \\
\text { significance }\end{array}$ & $\begin{array}{c}\text { Foraging source } \\
\text { for honey bees }\end{array}$ \\
\hline Aegle marmelos & Bael & $x$ & & $x$ & $x$ \\
\hline Aracardium occidentale & Cashew & $x$ & & & $x$ \\
\hline Annona reticulata & Ramaphal & $x$ & & & $x$ \\
\hline Annona squamosa & Sitaphal & $x$ & & & $x$ \\
\hline Artocarpus altilis & Breadfruit & $x$ & & & $x$ \\
\hline Artocarpus heterophyllus & Jackfruit & $x$ & & & $x$ \\
\hline Azadirachta indica & Neem & & $x$ & $x$ & $x$ \\
\hline Bergera koenigii & Curry leaf & $x$ & & & $\mathrm{x}$ \\
\hline Citrus maxima & Grapefruit & $x$ & & & $x$ \\
\hline Citrus medica & Nimbu & $x$ & $x$ & $\mathrm{x}$ & $x$ \\
\hline Citrus reticulata & Mandarin orange & $x$ & & $x$ & $x$ \\
\hline Cocos nucifera & Coconut & $x$ & & $x$ & $x$ \\
\hline Litchi chinensis & Lychee & $x$ & & & $x$ \\
\hline Mangifera indica & Mango & $x$ & & $x$ & $x$ \\
\hline Manilkara zapota & Sapota & $x$ & & & $\mathrm{x}$ \\
\hline Moringa oleifera & Drumstick & & & & $x$ \\
\hline Muntingia calabura & Singapore cherry & $\mathrm{x}$ & & & $x$ \\
\hline Persea americana & Avocado & $x$ & & & $x$ \\
\hline Phoenix sylvestris & Wild date palm & $x$ & & $x$ & $x$ \\
\hline Phyllanthus acidus & Malay gooseberry & $x$ & & & $x$ \\
\hline Phyllanthus emblica & Indian gooseberry & $x$ & & & $x$ \\
\hline Pithecellobium dulce & Manila tamarind & $x$ & & & $x$ \\
\hline Prunus domestia & Plum & $x$ & & & $x$ \\
\hline Psidium guajava & Guava & $x$ & & & $x$ \\
\hline Punica granatum & Pomegranate & $x$ & & & $x$ \\
\hline Pyrus spp. & Pear & $x$ & & & $x$ \\
\hline Santalum album & Sandalwood & & $x$ & $x$ & \\
\hline Sapindus trifolatus & South Indian ritha & & $x$ & $\mathrm{X}$ & \\
\hline Syzygium cumini & Indian blackberry & $x$ & & & $x$ \\
\hline Syzigium jambos & Pannnerale & $x$ & & & \\
\hline Tamarindus indica & Indian tamarind & $x$ & & $x$ & \\
\hline
\end{tabular}


large green open spaces such as parks, community gardens, remnant forest patches, sacred grooves, botanical gardens and institutional gardens. Domestic gardens refers to small patches of private gardens associated with residential homes, flats and township which contribute significantly to urban green spaces. Despite of the small size and heterogenous nature, urban domestic gardens contribute substantially to land use category. The plant and tree cover

Table 2: Plants (shrubs and herbs) recorded from single domestic gardens and shared apartment gardens in Bengaluru that are consumed as food and/or have medicinal use and/or religious significance and provision of foraging sources for honey bees. Modified after Jaganmohan et al. (2012).

\begin{tabular}{|c|c|c|c|c|c|}
\hline Scientific name & $\begin{array}{l}\text { Common } \\
\text { name }\end{array}$ & $\begin{array}{l}\text { Consumed } \\
\text { as food }\end{array}$ & $\begin{array}{c}\text { Medicinal } \\
\text { use }\end{array}$ & $\begin{array}{l}\text { Religious } \\
\text { significance }\end{array}$ & $\begin{array}{l}\text { Foraging source } \\
\text { for honey bees }\end{array}$ \\
\hline Abelmoschus esculentus & Lady's finger & $\mathrm{X}$ & & & $x$ \\
\hline Allium cepa & Onion & $x$ & & & \\
\hline Aloe vera & Aloe & & $\mathrm{X}$ & & \\
\hline Ananas comosus & Pineapple & $x$ & & & \\
\hline Bergera koenigii & Curry leaves & $\mathrm{x}$ & & & $x$ \\
\hline Beta vulgaris & Beetroot & $x$ & & & \\
\hline Brassica juncea & Mustard & $x$ & & & $\mathrm{x}$ \\
\hline Brassica rapa & Turnip & $\mathrm{x}$ & & & \\
\hline Capsicum spp. & Chilly & $x$ & & & $x$ \\
\hline Carica papaya & Papaya & $x$ & & & $x$ \\
\hline Cinnamomum verum & Cinnamon & $\mathrm{x}$ & $\mathrm{X}$ & & \\
\hline Citrus spp. & Lemon & $\mathrm{x}$ & & & $x$ \\
\hline Coccinia grandis & Ivy gourd & $x$ & & & $x$ \\
\hline Coffea arabica & Coffee & $x$ & & & $x$ \\
\hline Coriandrum sativum & Coriander & $x$ & $\mathrm{X}$ & & \\
\hline Curcuma longa & Turmeric & $x$ & $x$ & $\mathrm{X}$ & \\
\hline Cymbopogon citratus & Lemon grass & $x$ & $x$ & & \\
\hline Elettaria cardamomum & Cardamom & $\mathrm{x}$ & & & $x$ \\
\hline Hibiscus cannabinus & Gongura & $x$ & & & $x$ \\
\hline Hibiscus rosa-sinensis & Hibiscus & & $x$ & $x$ & $x$ \\
\hline Jasminum spp. & Jasmine & & & $x$ & $x$ \\
\hline Lablab purpureus & Avarekalu & $x$ & & & $x$ \\
\hline Lawsonia inermis & Mehendi & & $x$ & $\mathrm{X}$ & \\
\hline Manihot esculenta & Tapioca & $x$ & & & $x$ \\
\hline Mentha spicata & Mint & $x$ & $\mathrm{x}$ & & \\
\hline Momordica charantia & Bitter gourd & $x$ & $\mathrm{x}$ & & $x$ \\
\hline Moringa oleifera & Drumstick & $x$ & & & $x$ \\
\hline Musa paradisiaca & Banana & & & & $x$ \\
\hline Ocimum tenuiflorum & Holy basil & & $\mathrm{x}$ & $\mathrm{x}$ & $x$ \\
\hline Passiflora edulis & Passion Fruit & $x$ & & & $x$ \\
\hline Piper betle & Betel & $x$ & $x$ & $x$ & \\
\hline Piper nigrum & Pepper & $x$ & $x$ & & \\
\hline Plectranthus amboinicus & Dodda patre & & $\mathrm{x}$ & & \\
\hline Portulaca oleracea & Doddagoni soppu & $x$ & & & \\
\hline Raphanus sativus & Radish & $x$ & & & \\
\hline Rauvolfia serpentina & Sarpagandha & & $\mathrm{X}$ & & \\
\hline Ruta chalepensis & Naagdali & & $x$ & & \\
\hline Saccharum officinarum & Sugar cane & $x$ & & & \\
\hline Solanum lycopersicum & Tomato & $x$ & & & $x$ \\
\hline Solanum melongena & Brinjal & $x$ & & & $x$ \\
\hline Spinacia oleracea & Spinach & $x$ & & & \\
\hline Vitis vinifera & Grapes & $x$ & & & $\mathrm{x}$ \\
\hline Zea mays & Corn & $x$ & & & $x$ \\
\hline Zingiber officinale & Ginger & $x$ & & & \\
\hline
\end{tabular}


in this garden provides habitats and sustain urban biodiversity including birds, insects, vertebrates and invertebrates. Domestic gardens also improve the synergy with adjacent locations and increase species richness in adjacent urban parks.

The study by Jaganmohan et al. (2012) revealed that rose (Rosa spp.), found in $23 \%$ of sampled locations, Anthuriums (Anthurium spp.), also encountered in $23 \%$ of sampled locations, Areca palm (Chrysalidocarpus lutescens), found in $26 \%$ ofsampled locations, Hibiscus (Hibiscusrosa-sinensis), found in $27 \%$ of sampled locations andholy basil or tulasi (Ocimum tenuiflorum), found in $41 \%$ of sampled locations, as well as onetree species, coconut (Cocos nucifera), found in $31 \%$ of locations across Bengaluru. The majority of species were ornamental. $35 \%$ of tree species (Table 1 ) and $23 \%$ of plant species (Table 2 ) were used for food or medicine, or had religious significance. The predominant use is for food, with 28 tree species and 36 plant species providing fruits, vegetables or spices used for cooking (Jaganmohan et al., 2012).

Parks, community spaces, institutions and avenues: Tree Diversity

The tree diversity is found to be rich Bengaluru and considered as an urban forest with high species richness in parks and residential areas (Fig 4). An urban forestry study revealed 374 species with highest species diversity in parks (291) followed by residential areas and layouts (164). Polyalthia sp. and Pongamia glabra are the most dominant species in parks though their relative density is lesser in the larger parks. Polyalthia $s p$. is also dominant in institutions and offices to the extent of a relative density of 21 to $34 \%$. Institutions are dominated by fast growing species (Polyalthia longifolia, Grevillea robusta, Bauhinia variegata), decorative trees (Delonix regia, Tabebuia argentea) and shade-giving trees (Samanea saman) (Sudha and Ravindranath 2000).

\section{Flat and apartments, open gardens and community} spaces

Sudha and Ravindranath (2000) identified a total of 164 species in different residential areas in Bengaluru, the 10 dominant species accounted for $58 \%$ of the trees. The predominant species in the higher strata are Cocos nucifera, Murraya koenigii, Psidium guajava and Polyalthia longifolia. In the lower strata, the dominant species are Cocos nucifera, Moringa oleifera, Musa paradisiaca and Mangifera indica (Sudha and Ravindranath 2000).

\section{Trees in house compounds}

The top 15 predominant species in compounds of residences account to $77 \%$ of the total trees in compounds. Cocos nucifera is the predominant species, accounting for $18 \%$, followed by Murraya koenigii, Musa paradisiaca. Moringa oleifera and Carica papaya. Polyalthia longifolia and Michelia champaca, which are ornamental and fruityielding varieties includes, Cocos nucifera, Carica papaya, Psidium guajava,
Mangifera indica, Punica granatum, Annona squamosa, Citrus limon and Artocarpus integrifolius. Two species are used in cooking; Moringa oleifera as a vegetable and Murraya koenigii leaves for seasoning. Ricinus communis grows more as a weed in the compounds of houses of the higher income group and also in the wastelands around houses in the lower income areas (Fig 2; Sudha and Ravindranath 2000).

\section{Avenue trees in residential areas}

The avenue trees account for $28 \%$ of the trees in the residential land-use category of the 87 species, the top 15 tree species account for $80 \%$ of the total avenue trees. The trees most preferred by the Social Forestry Scheme are Michelia champaca, Bauhinia variegata, and Pongamia glabra. Moringa oleiferais found in abundance in the lower income residential areas along avenue (Sudha and Ravindranath 2000).

\section{Honey bee diversity in Bengaluru}

The identified honey bees include Apis indica, Apis dorsata, Apis florea and Trigona iridipennis (Fig 5, 6). The species nest with single comb include dwarf honey bee Apis florea and gaint honey bee Apis dorsata.

\section{Apis florea}

The $A$. florea species mainly distributed in warm climates. As its name implies, the dwarf honey bee is the smallest species of honey bee in body size and nest size. The nest of $A$. florea consist of a single comb whose upper part expands to form a crest that surround the branch. Most of the nests are hung from slender branches of trees or shrubs covered with relatively dense foliage usually from 1 to 8 meters above the ground. Combs of the dwarf honey bees are well covered with layers of worker clinging to form many layers. which act as a living protective curtain and shows shimmering movements when disturbed. In comparison with other honey bees, the amount of honey stored by Apis florea is very less accounting to 700 to $800 \mathrm{~g}$ depending on the locations and floral availability. The life cycle and behaviour of this species is fairly similar to other species of Apis.

\section{Apis dorsat}

oneybees are found near in or near forest and towns. Apis dorsata is the largest of all honey bees. The bee shares the open air and single comb nesting suspending its nest from the under surface of its support. Usually the $A$. dorsata tends to nest high in the air (3-25 meters above the ground). They also prefer long and branched trees as a safe nesting site and perfuse branching to avoid the access of terrestrial predators. Around three quarter of the worker population is employed for colony defence forming a protective curtain three to four bees thick. The nests are exposed and not hidden in dense foliage unlike in A. florea. Around 10-20 colonies can be seen in a single colony depending on the size and branching patter of the tree which is often referred as "bee tree". The organization of the comb is similar to 


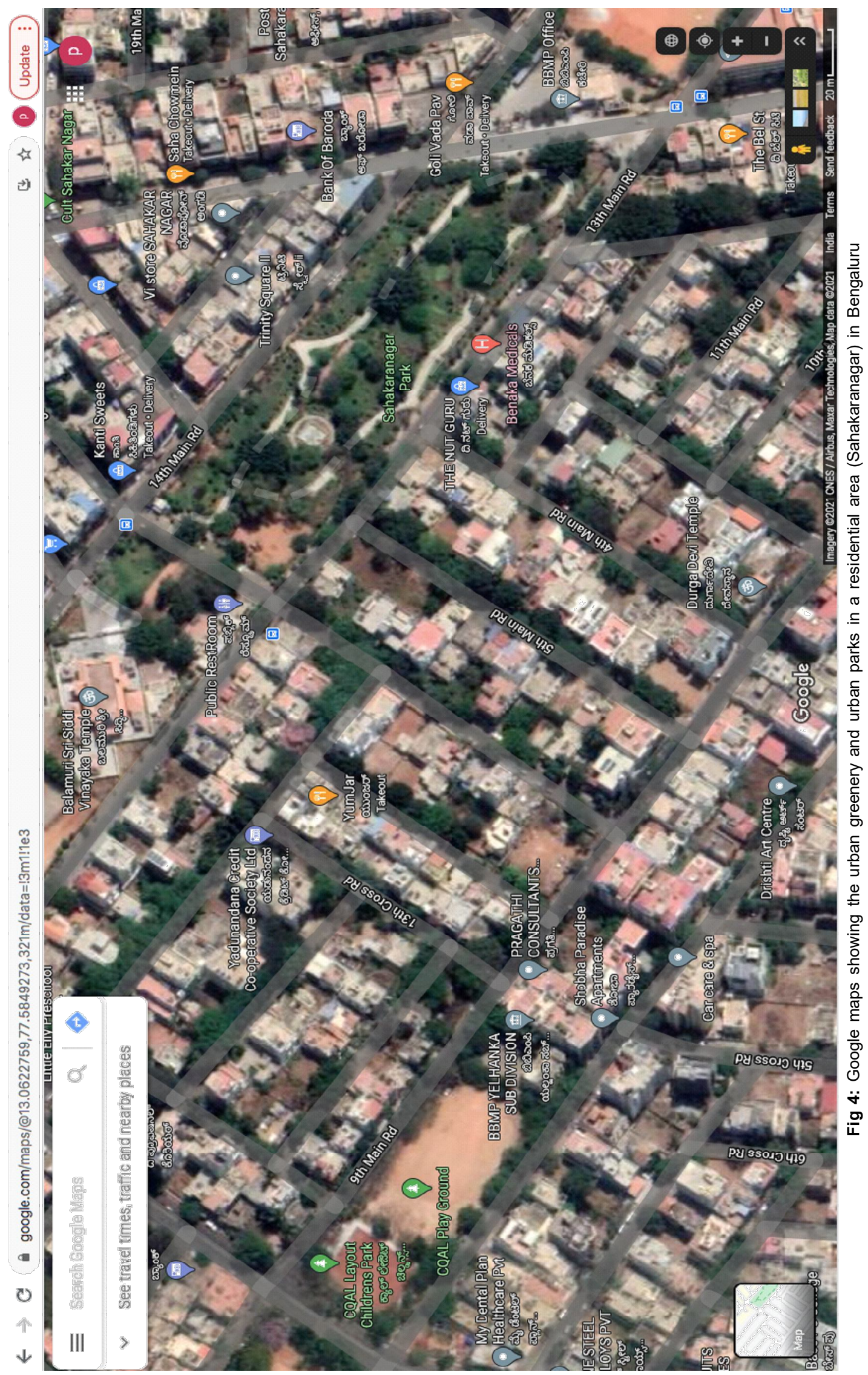


Honey Bee Diversity in Urban and Peri-urban Agriculture and Urban Forest- Outlook Study from Bengaluru-Silicon Valley of.....

Apis indica; honey storage at the top, followed by pollen storage, worker brood and drone brood. The active area is the lower part of the nest called "mouth" were workers move frequently and communicate with bee dance mechanisms. In many places in Bengaluru, the arrival of $A$. dorsata is an annual event occurring at the end of the rainy season or at the beginning of the dry season. $A$. dorsata is famous for its ferociousness when its nest is disturbed due to predators or natural climatic disturbances. The defending workers can peruse attackers or nearby living things over long distances which is even fatal to human beings, livestock's or other wild animals even elephants. The intensification of the bee hunting and unscientific and crude collection methods often threat the existence of $A$. dorsata in Bengaluru. Rockbees can even forage during moonlit nights and flight range is more than $5 \mathrm{~km}$.

Rockbees adapt themselves to living near human societies especially manufacturing factories, dams, highrise buildings and temples, churches etc. Rockbee was has lower melting point $\left(59.6^{\circ} \mathrm{C}\right)$ than $A$. cerena or $A$. mellifera bee wax. The pollen is usually wasted during honey collection could be used as a commercial product for food supplements as bee feed in apiculture, in dearth management, human therapeutics and nutrition. Rock bees can be considered as an important pollinator of many crops and agroforestry tress due to long proboscis, large flight range, larger workforce, ability to collect larger quantities of pollen and nectar. Its aggressive behaviour and migratory habit have serious problem in manipulating planned pollination programmes for field crops.

\section{Apis cerana}

The Apis cerana of the Asiatic honeybee (Eastern honey bee) are widely domesticated and cultivated in southern and south-eastern Asia. For many centuries the Apis cerana provide the mankind with honey, beewax and pollination of agricultural crops and various ecosystem services. Apis cerena distribution is much wider when compared to $A$. florea and Apis dorsata and found throughout tropical, subtropical and temperate zones of Asia. In the wild conditions, Apis cerena construct multiple-comb nest in dark enclosures such as caves, rock cavities and hollow tree trunks not more than 4-5 meters high above the ground. The combs of $A$. cerena are built parallel to each other with uniform distances known as "bee space". Following the invention of movable-frame hive for the European honeybee about a century ago, traditional bee keeping with $A$. cerena has been enriched with modern scientific methods in many Asian countries. In Karnataka and Tamil Nadu, there is a strong traditional beekeeping in Coorg and Marthandam. In Kerala, especially the rubber growing areas migratory bee keeping is practiced from a long time collect the extra floral nectar.

\section{Apis mellifera}

The Western Honeybee or European honeybee (Apis mellifera) is commonly domesticated and cultivated across the Europe and name "Mellifera" is from Latin and means honey carrying. These bees are widely introduced to many Asian countries for massive rearing and honey production. Outside Asia, beekeeping with $A$. mellifera is an integral part of modern agricultural systems with emphasis to pollination, ecosystem services, honey and bee wax production. The introduction of $A$. mellifera encountered many problem of inter-species transmission of diseases and pests and emergence of many new predators. However when comparing commercial viability, economic profitability and income generation to farmers; many successes stores were reported from various Asian countries including many parts across India. The European bee is similar to the Indian bee in its biology, nesting, foraging, colony defence and other behavioural features with some minor differences.
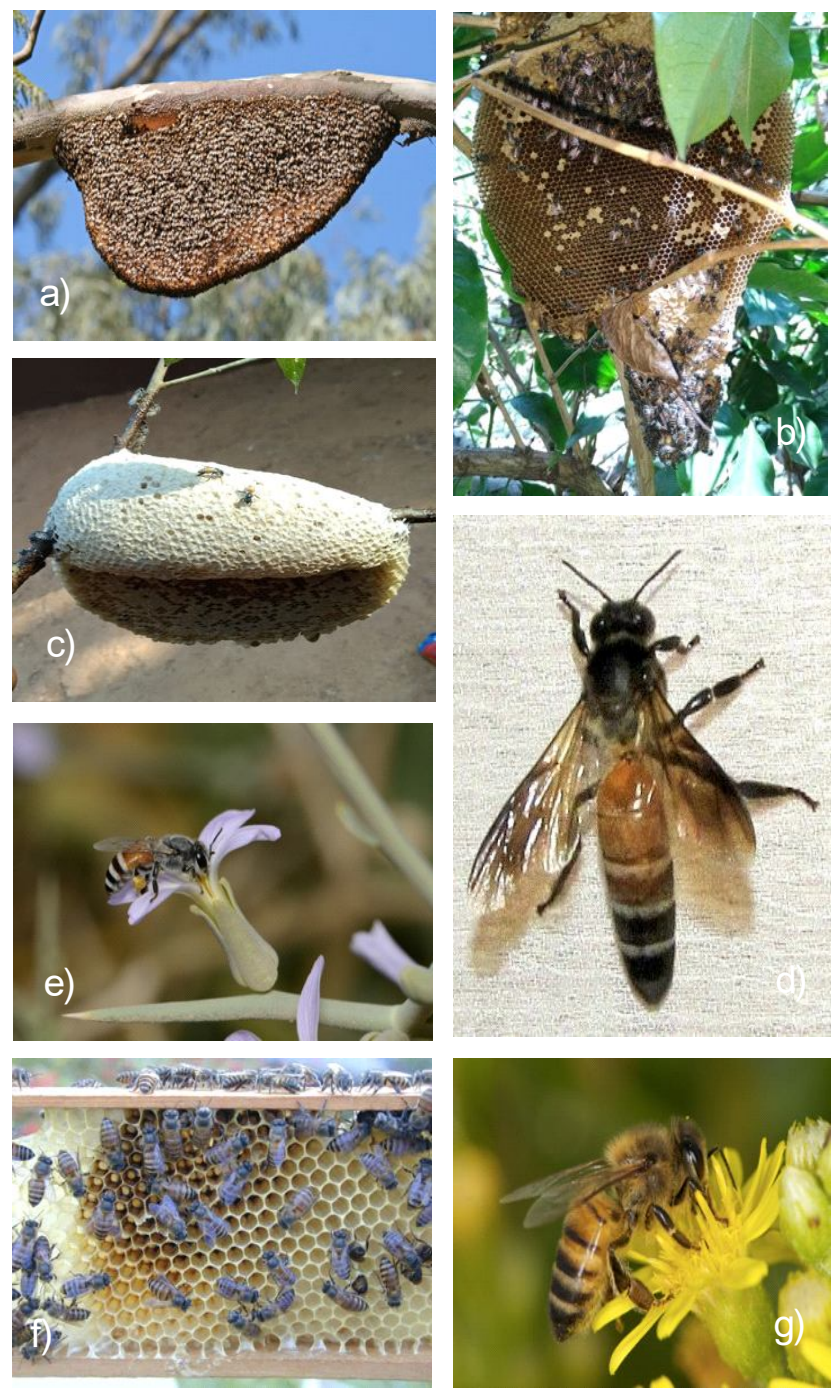

Fig 5: Description of the different honeybees identified in Bengaluru a) Rockbees; Apis dorsatab) Apis florea comb showing the brood; c) Apis florea brood showing honey storage area; d) Apis dorsata worker bee e) Apis florea worker bee f) Apis cerena colony showing brood and stored honey and pollen g) Apis mellifera collecting pollen and nectar. 
Honey Bee Diversity in Urban and Peri-urban Agriculture and Urban Forest- Outlook Study from Bengaluru-Silicon Valley of.....

\section{Trigona iridipennis (Stingless bees)}

Usually stingless bees were seen in building foundations, mud walls, stone walls and tree cervices. They prefer tropical climate. Also seen in tropical places especially Mexico to Argentina and Indo-Australian regions especially India, Sri Lanka and Taiwan (Sakagami 1982; Wille et al. 1983). The most prominent stingless bees seen in India is Trigona iridipennis species (Swaminathan 2000). Before they were known as Melipona iridipennis. Now the species located in India and Sri Lanka belong to Trigona genus and this classification is widely accepted (Michener 1974; Sakagami 1978). These bees got the name Trigona iridipennis due to triangular abdomen and iridescent wings. For building nest, they collect resins from trees which makes them called as Dammer bees. In India especially villages and among tribal people of Kerala and Karnataka, stingless bees were domesticated but not much importance and attention were for the management of these bees. Much importance are given to the large scale production of Apis indica and Apis mellifera in Kerala and Karnataka. Stingless bees were much far ahead of medicinal properties of honey and plant pollination when compared to other honey bees (Garedew et al. 2004). Even though the stingless bee produce less quantity of honey $(400-600 \mathrm{ml})$, due to high medicinal property of their honey, smooth taste and fragrance make them superior than other types of honey. The importance of stingless bee pollination is much higher than the value of their honey produced. There are lot of small plant that depend only on stingless bees for their pollination (Heard 1999). The body of the stingless bees were designed to collect pollen and nectar from very small flowers. The stingless bee travel only around $800 \mathrm{~m}$ radius for collecting pollen and nectar which make them suitable for controlled pollination. Stingless bees could be effectively used for green houses, poly houses and controlled farming techniques. The small bees do not get much appreciation and preferences for their valuable services. For house yard honey culture these small bees could be effectively utilized due to their special features and biodiversity in Kerala and Karnataka.

\section{Pollen and nectar sources for honey bees}

Honey bees collect nectar and pollen from a variety of plant species especially woody trees, fruit trees, ornamental and medical plants, weed plants and vegetable crops (Table 1, 2). Some of the plants supply nectar and pollen through-out the year while others are only seasonal. Due to the small size, the stingless bees can collect nectar and pollen from very small flowers where other honey bee species fail to do.

\section{Natural habitat of stingless bees in Bengaluru}

The stingless bees are found naturally abundant in stone walls, mud walls wooden logs, telephone posts, galvanized iron (GI) pipes in and around various areas in Bengaluru (Fig 6). They are abundant in GKVK campus, old churches made with stone and serval anthropogenic habitats. These are natural feral colonies which cannot be easily collected un-less special education techniques or destructive methods used (Vazhacharickal and Jose 2016, 2018).

\section{Integration of honey bees and stingless bees in urban} agriculture and urban forest

The adaptability of the bees, appropriate bee keeping technology, forage ecology and socio-economic suitability are very important in popularisation of apiculture. Stingless bees could be successfully integrated into the urban farming systems without much complications especially in balcony, terrace as well as kitchen gardens. In addition, they could be also use to serve the urban forests especially parks, roadside avenues, temples and other worshiping places, institutions with campus and even in the flats with community parks and gardens. The stingless bees needs minimum space and attention and could be easily handled by women, children and aged persons without any difficulty. The stingless bees could be placed on balconies, open terraces or in the garden which could marginally improve pollination,
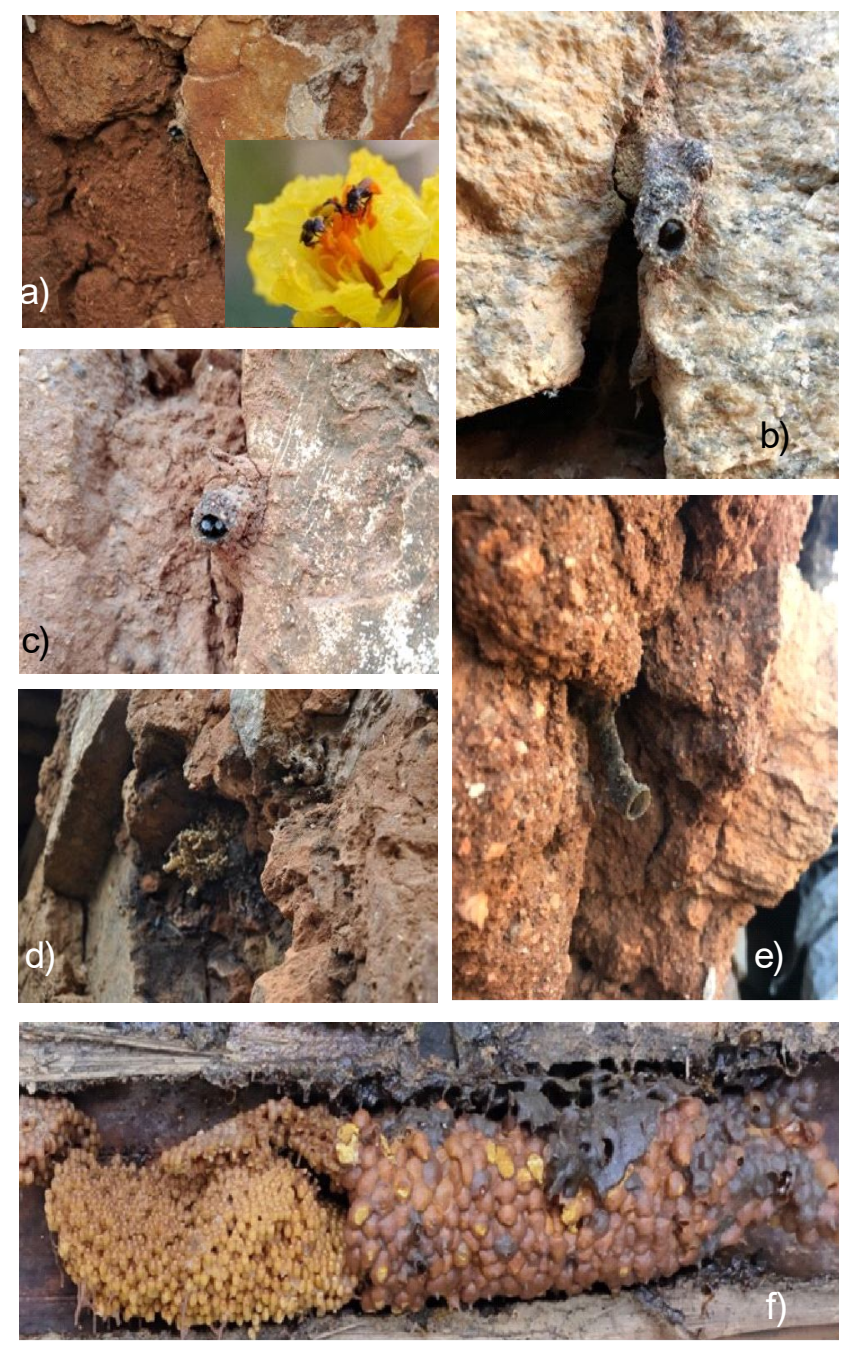

Fig 6: Description of the stingless bees across Bengaluru a) natural habitat on mud walls; b) habitat on stone walls; f) colony showing brood and stored honey and pollen. 
Honey Bee Diversity in Urban and Peri-urban Agriculture and Urban Forest- Outlook Study from Bengaluru-Silicon Valley of.....

crop yield and ecosystem services. A single stingless bee colony can yield $400-500 \mathrm{~g}$ of pure honey which can fetch to 18-20 US\$ per yield (Vazhacharickal et al., 2020). Moreover, while integrating stingless bees into the urban environment; provide leisure time activity and mental enchantment for the retired persons and collection pure home honey with high medical properties.

\section{Possible outcomes of integration}

The urban agriculture and urban forest system in the Bengaluru are ideal for stingless bee keeping. These provide a wide variety for foraging sources for the stingless bees. Currently these floral resources are being underutilized; utilized only for aesthetic beauty and integration of stingless bees will definitely utilize the various floral resources. The pollination services proved by these bees will have a definitely impact on the urban agriculture productivity, size and quality of the fruit and better utilization the resources.

\section{CONCLUSION}

In conclusion, the outlook study provide insights into the unique importance of urban domestic gardens and urban forests for the support of biodiversity in a rapidly expanding urban area Bengaluru the silicon valley of India. They point to the importance of large gardens and of traditional practices of urban agriculture and gardening that encourage the planting of culturally important species, flowering plants and species of food value, but also indicate the changes that are taking place as many gardens shrink in size, disappear, or become converted to apartments which contain greater numbers of ornamental non-flowering plants and trees with diminished biodiversity value. These gardens can be very important at a coarse scale, acting as networks to support biodiversity, promote ecosystem services, provide nectar and pollen to honey bees and other pollinating and non-pollinating insects as well as birds. Urban agriculture and urban forest system in the Bengaluru are ideal for stingless bee keeping and provide them with nectar and pollen. Since natural feral stingless bees can been in many places in and around Bengaluru, they may be considered as resilient to the urban environment. The integration of stingless bees will definitely improve the pollination in the urban gardens and urban forest which in turn have a clear impact of the fruit productivity, fruit size and seed setting. Stingless bees could be easily reared with limited space and care and provide a leisure time activity for the retired person, women and children. More over the possible pollination services offered by integrating these little bees cannot be foreseen in the Silicon valley of India.

\section{ACKNOWLEDGMENT}

This outlook study will not be possible by the encouragement and support from Dr. K.B. Umesh, Dr. Andreas Buerkert, Dr. Prasanna Kumar P.S, Dr. Veerabhadrappa Bellundagi, Dr. Hamsa K.R. and Dr. Catrin Westphal.

\section{Declarations}

\section{Funding}

No funding was received to assist with the preparation of this manuscript.

\section{Conflicts of interest}

The authors do not have any conflict of interest.

\section{REFERENCES}

Abrol, D.P. (2013). Beekeeping: A Compressive Guide to Bees and Beekeeping. Scientific Publishers, New Delhi.

Brinkmann, K., Hoffmann, E. and Buerkert, A. (2020) Spatial and temporal dynamics of Urban Wetlands in an Indian Megacity over the past 50 years. Remote Sensing. 12(4): 1-33.

Cardinal, S., Danforth, B.N. (2011). The antiquity and evolutionary history of social behaviour in bees. PLOS one. 6(6): e21086.

Cohen, B. (2006). Urbanization in developing countries: current trends, future projections and key challenges for sustainability. Technology in Society. 28(1): 63-80.

De Zeeuw, H., van Veenhuizen, R., Dubbeling, M. (2011). The role of urban agriculture in building resilient cities in developing countries. The Journal of Agricultural Science. 149(S1): 153-163

Fernandes, L., Heller, P. (2006). Hegemonic aspirations: New middle class politics and India's democracy in comparative perspective. Critical Asian Studies 38(4): 495522.

Frazier, C. (2018). Grow what you eat, eat what you grow: Urban agriculture as middle class intervention in India. Journal of Political Ecology 25(1): 221-238.

Garedew, A., Schmolz, E., Lamprecht, I. (2004). Microbiological and calorimetric investigations on the antimicrobial actions of different propolis extracts: An in vitro approach. Thermochimica Acta. 422(1-2):115-124.

Gowda, U.R., Chandrakanth, M.G., Srikanthamurthy, P.S., Yadav, C.G., Nagaraj, N., Channaveer (2012). Economics of PeriUrban Agriculture: Case of Magadi Off Bangalore. Economic and Political Weekly 1: 75-80

Grinspan, D. (2015). Urban gardening practices in Bangalore: towards a more localized food system? Independent Study Project (ISP) Collection. 2079.

Heard, T.A. (1999). The role of stingless bees in crop pollination. Annual Review of Entomology. 44(1): 183-206.

Hoffmann, E., Jose, M., Nölke, N., Möckel, T. (2017). Construction and use of a simple index of urbanization in the rural-urban interface of Bangalore, India. Sustainability. 9(11): 1-21.

Jaganmohan, M., Vailshery, L.S., Gopal, D. and Nagendra, H. (2012) Plant diversity and distribution in urban domestic gardens and apartments in Bangalore, India. Urban Ecosystems. 15(4): 911-925.

Kraft, T.S., Venkataraman, V.V. (2015). Could plant extracts have enabled hominins to acquire honey before the control of fire? Journal of Human Evolution. 85: 65-74.

Lee-Smith, D. (2010). Cities feeding people: an update on urban agriculture in equatorial Africa. Environment and Urbanization 22(2): 483-499.

Michener, C.D. (1974). The Social Behavior of the Bees: A Comparative Study. Harvard University Press. 
Honey Bee Diversity in Urban and Peri-urban Agriculture and Urban Forest- Outlook Study from Bengaluru-Silicon Valley of.....

Mougeot, L.J.A. (2000). Urban agriculture: definition, presence, potentials and risks. In: [Bakker N, Dubbeling M, Guendel S, Sabel Koschella U, De Zeeuw H (eds.)] Growing Cities, Growing Food: Urban Agriculture on the Policy Agenda. Deutsche Stiftung für internationale Entwicklung (DSE), Feldafing, pp 1-42.

Nath, V. (2007). Urbanization, urban development and metropolitan cities in India. Concept Publishing Company, New Delhi.

Nugent, R. (2000). The Impact of Urban Agriculture on the Household and Local Economies. In: Growing Cities, Growing Food: Urban Agri-culture on the Policy Agenda. [Bakker, N., Dubbeling, M., Guendel, S., Sabel Koschella, U., De Zeeuw, $H$. (eds.)]. Deutsche Stiftung für internationale Entwicklung (DSE), Feldafing, pp. 67-98.

Ramachandra, T.V., Kumar, U. (2008). Wetlands of greater Bengaluru, India: Automatic delineation through pattern classifiers. Electronic Green Journal. (26): 1-22.

Roopa, A.N., Gowda, G., Eswarappa, G., Vazhacharickal, P.J. (2020). Bio-ecology of Stingless bees, Trigona iridipennis Smith. (Hymenoptera: Apidae) in GKVK campus: an overview. Amzon Publishers, New York.

Sakagami, S.F. (1982). Stingless Bees. In: Social Insects, Vol. III (H.R. Hermann. Ed.) Academic Press, New York. pp. 361423.

Sakagami, S.F. (1978). Tetragonula Stingless Bees of the continental Asia and Sri Lanka (Hymenoptera, Apidae). Journal. Series 6. Zoology.

Satterthwaite, D., McGranahan, G., Tacoli, C. (2010). Urbanization and its implications for food and farming. Philosophical Transactions of the Royal Society B: Biological Sciences 365(1554): 2809-2820.

Sudha, P., Ravindranath, N.H. (2000). A study of Bangalore urban forest. Landscape and Urban Planning 47(1-2): 47-63.

Sudhira, H.S., Ramachandra, T.V., Subrahmanya, M.B. (2007). Bengaluru. Cities 24(5): 379-390.

Swaminathan, T. (2000). Studies on stingless bees (Doctoral dissertation, Tamil Nadu Agricultural University, Coimbatore).
Timalsina, K.P. (2007). Rural urban migration and livelihood in the informal sector: A study of street vendors of Kathmandu metropolitan city, Nepal. Norwegian University of Science and Technology, Trondheim, Norway.

UN (2019). World Urbanization Prospects - The 2018 Revision, United Nations (UN), NY, USA van Holstein, E. (2019). The social boundary work of new middle-class organic gardeners in Bangalore, India. Ur-ban Forestry and Urban Greening. 44: 126432

Vazhacharickal, P.J. (2014) Characterization of urban and periurban agriculture production systems and soil heavy metal signatures in the Mumbai metropolitan Region, India. Cuvillier Verlag, Goettingen.

Vazhacharickal, P.J., Buerkert. A. (2011). Sustainable cities: an overview of the urban and peri-urban agricultural production in Mumbai Metropolitan Region (MMR). Leituras de Economia Política (19): 69-87.

Vazhacharickal, P.J., Jose, S. (2016). Nesting behavior and habitats of the stingless bee Trigona iridipennis Smith in Kerala. Amazon Publishers, New York.

Vazhacharickal, P.J., Jose, S. (2018). Stingless bees culture (Meliponiculture) in Kerala: Hand book for farmers. Amazon Publishers, New York.

Vazhacharickal, P.J., Jagadish, K.S., Eswarappa, G. (2020). Possibility of Integrating Stingless Bees (Tetragonula iridipennis) into Urban and Peri-urban Agriculture and Urban Forest: Outlook Study from Bangalore-Silicon Valley of India. International Journal of Current Microbiology and Applied Science. 9(12): 2662-2669.

Weber, C., Puissant, A. (2003). Urbanization pressure and modelling of urban growth: Example of the Tunis Metropolitan Area. Remote Sensing of Environment. 86(3): 341-352. 